\title{
Analisa Keandalan Sistem Distribusi 20 kV PT.PLN Rayon Lumajang dengan Metode FMEA (Failure Modes and Effects Analysis)
}

\author{
Achmad Fatoni, Rony Seto Wibowo, Adi Soeprijanto \\ Jurusan Teknik Elektro, Fakultas Teknologi Industri, Institut Teknologi Sepuluh Nopember (ITS) \\ Jl. Arief Rahman Hakim, Surabaya 60111 Indonesia \\ e-mail: ronyseto@ee.its.ac.id, adisup@ee.its.ac.id
}

\begin{abstract}
Abstrak-Saat ini tingkat keandalan dari suatu sistem distribusi adalah sangat penting guna menjamin kontinuitas supply tenaga listrik kepada konsumen. Karena itu, disadari pentingnya otomatisasi sistem distribusi yang salah satunya dapat dicapai dengan menggunakan sectionalizer. Tugas Akhir ini dibuat dengan tujuan menghitung indeks keandalan dari sistem distribusi $20 \mathrm{kV}$ Rayon Lumajang. Metode yang digunakan adalah FMEA (Failure Mode and Effect Analysis), di mana indeks kegagalan dari setiap peralatan utama sistem distribusi diperhitungkan dalam mencari indeks keandalan sistem secara menyeluruh. Sejumlah studi kasus dilakukan guna melihat pengaruh dari jumlah serta lokasi penempatan sectionalizer dan juga fuse di sepanjang jaringan terhadap indeks keandalan sistem. Pada akhirnya, solusi optimal akan memberikan nilai indeks keandalan sistem distribusi yang terbaik. Berdasarkan hasil analisa, dengan penambahan fuse pada penyulang sukodono dapat menaikkan Indeks Keandalan SAIFI yang semula bernilai 6.6088 menjadi bernilai 5.4176, lalu dengan adanya penambahan sectionalizer pada penyulang sukodono maka dapat menaikkan indeks keandalan SAIDI yang awalnya bernilai 7.6737 menjadi bernilai 6.4431 .
\end{abstract}

Kata Kunci-Sistem Distribusi, SAIDI, SAIFI, Otomatisasi, FMEA.

\section{PENDAHULUAN}

K ebijakan Energi Nasional bertujuan untuk menyediakan energi listrik serta menjaga kontinuitas penyalurannya. Permasalahan yang paling mendasar pada distribusi daya listrik adalah pada mutu, kontinuitas dan ketersedian pelayanan daya listrik pada pelanggan. Penggunaan evaluasi keandalan sistem pada jaringan distribusi $20 \mathrm{kV}$ merupakan salah satu faktor yang penting untuk meningkatkan dan menjamin penanganan secara benar terhadap permasalahan yang real terjadi dilapangan, sehingga dapat diantisipasi terjadinya gangguan serta mengurangi kerugian akibat energi yang tidak tersupplai pada sistem distribusi.

Untuk mengetahui keandalan suatu penyulang maka ditetapkan suatu indeks keandalan yaitu besaran untuk membandingkan penampilan suatu sistem distribusi. Indeks-indeks keandalan yang sering dipakai dalam suatu sistem distribusi adalah SAIFI (System Average Interruption Frequency Index), SAIDI (System Average Interruption Duration Index), CAIDI (Customer Average Interruption Duration Index), ASAI (Average Service Availability Index). Sebagai acuan penentuan indeks yaitu berdasarkan Standar PLN yang nantinya digunakan sebagai tolok ukur tingkat keandalan system distribusi.
Salah satu cara mengetahui indeks keandalan yaitu dengan metode FMEA. Failure modes sendiri mengarah pada suatu langkah ataupun mode yang mengalami kegagalan, sedangkan effect analysis mengarah pada suatu studi yang membahas tentang konsekuensi dari kegagalan tersebut.

\section{KEANDALAN SISTEM DISTRIBUSI $20 \mathrm{KV}$}

\section{A. Definisi dan Teori Dasar Keandalan}

Keandalan (reliability) didefinisikan sebagai probabilitas dari peralatan atau sistem untuk dapat menjalankan fungsinya dengan semestinya, dalam kurun waktu tertentu, serta pada kondisi kerja tertentu. Dengan demikian, keandalan sistem distribusi berarti probabilitas sistem distribusi untuk dapat menjalankan fungsinya dengan semestinya, dalam kurun waktu tertentu, serta pada kondisi kerja tertentu.

\section{B. Keandalan dalam Sistem Distribusi Tenaga Listrik}

Tingkat keandalan dari sistem distribusi diukur dari sejauh mana penyaluran tenaga listrik dapat berlangsung secara kontinu kepada para pelanggan tanpa perlu terjadi pemadaman. Seiring dengan kemajuan zaman, terjadi pertumbuhan beban ditandai munculnya kawasan industri, bisnis, serta pemukiman yang baru, dan hal ini tentunya menuntut tingkat keandalan yang semakin tinggi.

\section{Istilah dalan Keandalan Distribusi}

Ada beberapa istilah yang penting berkaitan dengan keandalan sistem distribusi :

* Outage. Keadaan di mana suatu komponen tidak dapat melakukan fungsinya disebabkan hal-hal yang secara langsung berhubungan dengan komponen tersebut. Outage dapat atau tidak dapat mengakibatkan pemadaman bergantung pada konfigurasi sistem.

* Forced outage. Outage yang disebabkan oleh keadaan darurat yang secara langsung berhubungan dengan suatu komponen, di mana perlu agar komponen tersebut dilepaskan dari sistem dengan segera, atau outage yang disebabkan oleh kesalahan dalam pengoperasian peralatan ataupun karena kesalahan manusia

* Scheduled outage. Outage yang dihasilkan ketika suatu komponen dengan sengaja dilepaskan dari sistem pada waktu-waktu yang telah ditentukan, biasanya untuk tujuan perbaikan atau pemeliharaan berkala. 
* Interruption. Pemutusan kerja (pemadaman) pada satu atau lebih konsumen atau fasilitas sebagai akibat dari outage yang terjadi pada satu atau lebih komponen.

* Forced interruption. Pemadaman yang disebabkan oleh forced outage.

* Scheduled interruption. Pemadaman yang disebabkan oleh scheduled outage.

* Failure rate ( $\lambda$ ). Jumlah rata-rata kegagalan yang terjadi pada sebuah komponen dalam kurun waktu tertentu. Umumnya waktu dinyatakan dalam year dan failure rate dinyatakan dalam failurelyear

* Outage time (r). Waktu yang digunakan untuk memperbaiki atau mengganti bagian dari peralatan akibat terjadi kegagalan atau periode dari saat permulaan peralatan mengalami kegagalan sampai saat peralatan dioperasikan kembali sebagaimana mestinya (outage time umum dinyatakan dalam hours/failure).

* Annual outage time (U). Lama terputusnya pasokan listrik rata-rata dalam kurun waktu tertentu (umumnya annual outage time dinyatakan dalam hours/year)

\section{Failure Modes and Effects Analysis (FMEA)}

FMEA (Failure Modes and Effect Analysis) merupakan suatu bentuk pendekatan yang melibatkan analisa bottom-up, bertujuan mengidentifikasi modemode kegagalan penyebab kegagalan, serta dampak kegagalan yang ditimbulkan oleh tiap-tiap komponen terhadap sistem. Dengan kata lain, FMEA mempertimbangkan kegagalan sistem sebagai hasil dari kegagalan komponen-komponen penyusun sistem tersebut.

\section{E. Konsep Pendekatan Teknik}

Metode FMEA untuk mengevaluasi keandalan sistem distribusi didasarkan pada bagaimana kegagalan dari suatu peralatan sistem distribusi akan mempengaruhi keandalan sistem secara menyeluruh, sehingga untuk menentukan keandalan sistem dibutuhkan syarat-syarat sebagai berikut:

a. Hanya diperlukan satu deskripsi topologi jaringan. Sistem dapat didefinisikan dalam cabangcabangnya, komponen-komponennya, titik supply, dan titik beban/load point.

b. Untuk setiap komponen/peralatan diperinci data keandalan seperti indeks kegagalan (failure rate), waktu perbaikan (repair time), dan waktu switching (switching time).

c. Sectionalizer diperlakukan sebagai peralatan sistem dan alokasinya disesuaikan dengan topologi jaringan.

d. Penjumlahan dari pengaruh kegagalan setiap load point, baik itu failure rate, repair time, hal ini merupakan dasar rumusan dan perhitungan SAIFI, SAIDI, CAIDI.

\section{F. Prosedur Metode FMEA}

Flowchart pengerjaan FMEA terlihat pada gambar dibawah ini :

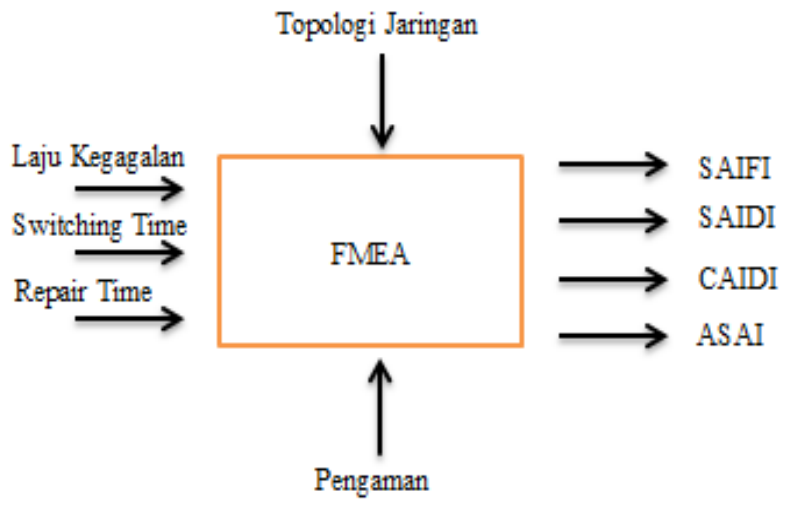

Gambar 1. Skema FMEA

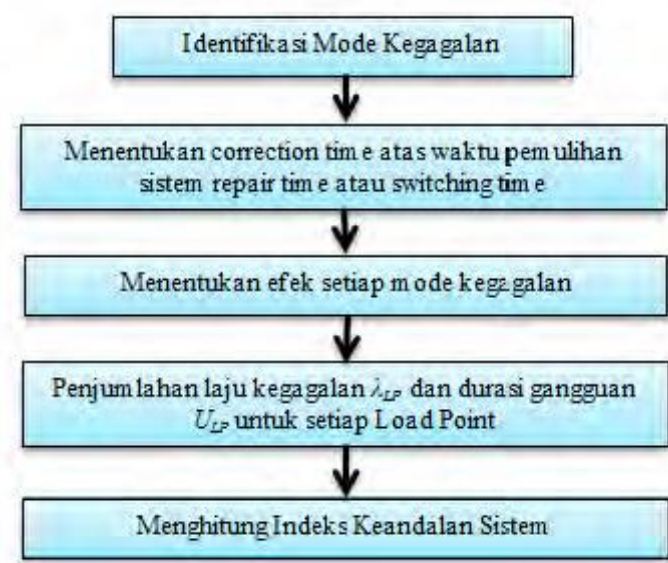

Gambar 2. Flowchart FMEA

\section{KEANDALAN JARINGAN DISTRIBUSI 20 KV PT. PLN RAYON LUMAJANG}

\section{A. Area Pelayanan PT. PLN wilayah Lumajang}

PT. PLN (persero) Rayon Lumajang mempunyai 12 penyulang yang disalurkan melaui 2 buah trafo penurun tegangan 150/20 kV dari Gardu Induk Lumajang yang masing-masing trafo 1 terdapat 7 buah penyulang yaitu penyulang jatiroto, penyulang pasirian, penyulang senduro, penyulang mustikatama, penyulang swandak, penyulang bumirejo, dan penyulang randuagung. Pada Trafo 2 terhubung dengan 5 penyulang yaitu penyulang klakah, penyulang sukodono, penyulang sudirman, penyulang keting, dan penyulang pronojiwo.

\section{B. Data Panjang saluran dan Pelanggan}

Berikut merupakan data panjang saluran dan jumlah pelanggan tiap penyulang pada trafo 2 :

TABEL 1. DATA PANJANG SALURAN DAN JUMLAH PELANGGAN

\begin{tabular}{cccc}
\hline \hline No. & Penyulang & Panjang SUTM $(\mathbf{k m s})$ & Jumlah Pelanggan \\
\hline 1 & Sukodono & 68.47 & 15662 \\
2 & Sudirman & 15.90 & 11506 \\
3 & Pronojiwo & 153.21 & 31514 \\
4 & Klakah & 160.33 & 22181 \\
5 & Keting & 80.38 & 25725 \\
\hline \hline
\end{tabular}

Dilihat dari kondisi kelistrikan kabupaten Lumajang bahwa konsumen utama kelistrikan adalah rumah tangga yang menempati sekitar $90 \%$ dan terus meningkat. Oleh karena itu keandalan dari sistim distribusi juga harus semakin ditingkatkan untuk menjaga kontinuitas dan kepuasan pelanggan 


\section{Standart Keandalan Sistem $20 \mathrm{kV}$}

Untuk mengukur suatu keandalan suatu system maka diperlukan patokan/standar yang berguna untuk menilai keadaan system dalam kondisi baik ataupun kurang baik. Maka berdasarkan standart PLN menurut majalah FOKUS penerbit PT.PLN februari 2011 menetapkan bahwa system dalam kondisi baik jika telah memenuhi standart seperti dibawah :

- SAIFI : $1,2 \mathrm{kali} /$ pelanggan/tahun

- SAIDI : 0,83 jam/pelanggan/tahun

Sedangkan menurut standart IEEE P1366-2003, nilai indeks keandalan telah memenuhi standart jika memenuhi

- SAIFI : 1,26 kali/pelanggan/tahun

- SAIDI : $1,9 \mathrm{jam} /$ pelanggan/tahun

Dan pada Parameter pengukuran Laju kegagalan dan juga Switching Time berdasarkan SPLN pada tahun 1985 tentang Keandalan system Distribusi $20 \mathrm{kV}$ dan $6 \mathrm{kV}$ yaitu :

\begin{tabular}{cccc}
\multicolumn{4}{c}{ TABEL 2. Standart Nilai Laju Kegagalan Dan RePAIR Time } \\
\hline \hline No. & Komponen & Laju Kegagalan & Repair Time (jam) \\
\hline 1 & Saluran Udara & $0,2 / \mathrm{km} /$ tahun & 4 \\
2 & Pemutus Tenaga & $0,004 /$ unit/tahun & 10 \\
3 & Sakelar Pemisah & $0,003 /$ unit/tahun & 10 \\
4 & Sakelar Beban & $0,003 /$ unit/tahun & 10 \\
5 & Trafo Distribusi & $0,005 /$ unit/tahun & 10 \\
\hline \hline
\end{tabular}

Operasi kerja waktu membuka menutup sakelar beban atau pemisah adalah $0.15 \mathrm{jam}$.

\section{Menghitung Indesks Keandalan}

Sedangkan indeks-indeks keandalan yang digunakan untuk menghitung performa keandalan sistem secara keseluruhan yaitu :

$>$ SAIFI (System Average Interruption Frequency Index) menginformasikan tentang frekuensi pemadaman rata-rata untuk tiap konsumen dalam kurun waktu setahun pada suatu area yang dievaluasi, cara menghitungnya yaitu total frekuensi pemadaman dari konsumen dalam setahun dibagi dengan jumlah total konsumen yang dilayani. Secara matematis dituliskan sebagai:

$$
\text { SAIFI }=\frac{\Sigma\left(\lambda_{i} \times N_{i}\right)}{\Sigma N}(\text { failure } / \text { year } * \text { customer })
$$

di mana:

$\lambda=$ indeks kegagalan rata-rata per tahu (failure/year) $\mathrm{N}=$ jumlah konsumen padam

SAIDI (System Average Interruption Duration Index) menginformasikan tentang durasi pemadaman rata-rata untuk tiap konsumen dalam kurun waktu setahun pada suatu area yang dievaluasi, cara menghitungnya yaitu total durasi pemadaman dari konsumen dalam setahun dibagi dengan jumlah total konsumen yang dilayani. Secara matematis dituliskan sebagai:

$$
S A I D I=\frac{\Sigma\left(U i \times N_{i}\right)}{\Sigma N}(\text { hours } / \text { year } * \text { customer })
$$

di mana:

$U=$ Durasi kegagalan rata-rata per tahun (hour/year) $\mathrm{N}=$ jumlah konsumen padam

CAIDI (Customer Average Interruption Duration Index) menginformasikan tentang durasi pemadaman rata-rata konsumen untuk setiap gangguan yang terjadi, cara menghitungnya yaitu SAIDI dibagi dengan SAIFI.

Secara matematis dituliskan sebagai :

$$
\text { CAIDI }=\frac{\text { SAIDI }}{S A I F I}(\text { hours } / \text { costumer } * \text { failure })
$$

\section{Evaluasi KEANDALAN Sistem Distribusi 20 KV PT. PLN RAYON LUMAJANG DENGAN FMEA}

\section{A. Model Sistem}

Model sistem penyulang Sukodono dari Trafo 2 seperti dibawah :

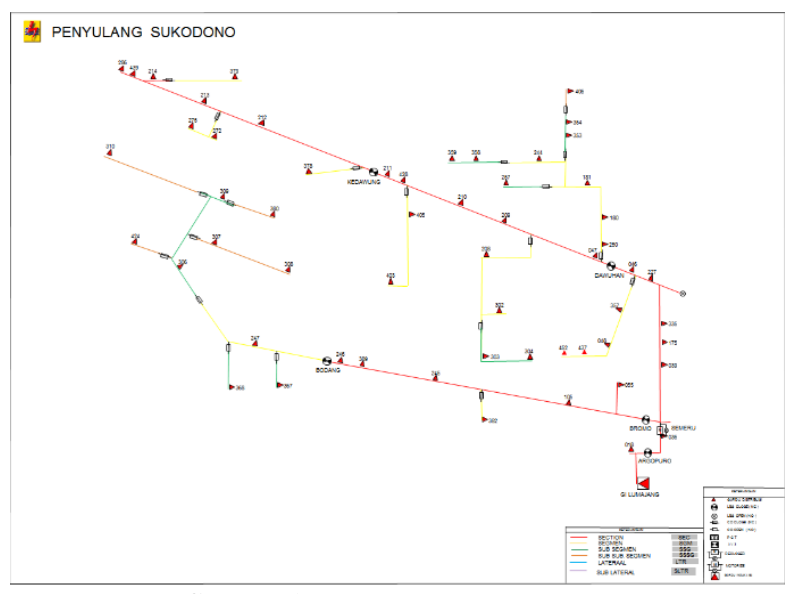

Gambar 3. SLD Penyulang Sukodono

\section{B. Data Saluran dan Jumlah Pelanggan}

\begin{tabular}{|c|c|c|c|}
\hline Load point & Trafo & Daya (KVA) & Jumlah Pelanggan \\
\hline 1 & GB018 & 200 & 778 \\
\hline 2 & GB036 & 200 & 466 \\
\hline 3 & GB039 & 100 & 72 \\
\hline 4 & GB175 & 250 & 914 \\
\hline 5 & GB335 & 100 & 304 \\
\hline 6 & GB227 & 50 & 499 \\
\hline 7 & GB357 & 50 & 166 \\
\hline 8 & GB048 & 160 & 533 \\
\hline 9 & GB437 & 100 & 530 \\
\hline 10 & GB452 & 200 & 209 \\
\hline 11 & GB046 & 160 & 612 \\
\hline 12 & GB250 & 160 & 465 \\
\hline 13 & GB180 & 50 & 146 \\
\hline 14 & GB181 & 160 & 530 \\
\hline 15 & GB257 & 160 & 465 \\
\hline 16 & GB353 & 50 & 103 \\
\hline 17 & GB354 & 25 & 43 \\
\hline 18 & GB406 & 50 & 65 \\
\hline 19 & GB244 & 50 & 178 \\
\hline 20 & GB358 & 50 & 132 \\
\hline 21 & GB359 & 50 & 74 \\
\hline 22 & GB047 & 160 & 499 \\
\hline 23 & GB208 & 50 & 169 \\
\hline 24 & GB302 & 100 & 293 \\
\hline 25 & GB303 & 100 & 176 \\
\hline 26 & GB304 & 100 & 217 \\
\hline 27 & GB209 & 100 & 204 \\
\hline
\end{tabular}

Data saluran dan Pelanggan sebagai berikut : TABel 3. Data SAluRan dan Pelanggan PenYulang SuKodono 


\begin{tabular}{|c|c|c|c|}
\hline 28 & GB210 & 50 & 130 \\
\hline 29 & GB405 & 100 & 241 \\
\hline 30 & GB403 & 100 & 211 \\
\hline 31 & GB428 & 100 & 105 \\
\hline 32 & GB211 & 160 & 499 \\
\hline 33 & GB378 & 100 & 168 \\
\hline 34 & GB212 & 50 & 210 \\
\hline 35 & GB272 & 25 & 99 \\
\hline 36 & GB275 & 50 & 138 \\
\hline 37 & GB213 & 100 & 164 \\
\hline 38 & GB214 & 100 & 544 \\
\hline 39 & GB379 & 50 & 105 \\
\hline 40 & GB439 & 100 & 410 \\
\hline 41 & GB286 & 1000 & 1 \\
\hline 42 & GB055 & 160 & 526 \\
\hline 43 & GB105 & 160 & 549 \\
\hline 44 & GB382 & 100 & 197 \\
\hline 45 & GB245 & 160 & 428 \\
\hline 46 & GB389 & 100 & 117 \\
\hline 47 & GB246 & 160 & 292 \\
\hline 48 & GB367 & 50 & 88 \\
\hline 49 & GB247 & 100 & 258 \\
\hline 50 & GB368 & 50 & 158 \\
\hline 51 & GB306 & 50 & 250 \\
\hline 52 & GB424 & 160 & 138 \\
\hline 53 & GB307 & 50 & 149 \\
\hline 54 & GB308 & 25 & 120 \\
\hline 55 & GB310 & 100 & 233 \\
\hline 56 & GB309 & 100 & 185 \\
\hline 57 & GB380 & 100 & 107 \\
\hline
\end{tabular}

Dengan mengacu pada data Laju Kegagalan, Repair Time, dan Switching Time sesuai stantart SPLN 1985.

\section{Hasil perhitungan Manual Excel Menggunakan FMEA}

Berikut merupakan hasil perhitungan manual Excel :

TABel 4. Hasil PeRhitungan MANUAL ExCEL FMEA

\begin{tabular}{|c|c|c|c|c|c|c|c|c|}
\hline & $\lambda$ & $\mathbf{U}$ & $\mathbf{N}$ & I & & CAI & AS & \\
\hline LP1 & 6.279 & 117 & 778 & 312 & 0.055 & 0.178 & 1.000 & 0.000 \\
\hline LP2 & 6.279 & 1.635 & 466 & 187 & 049 & 0.260 & 1.000 & 0.000 \\
\hline LP3 & 6.279 & 2.796 & & 029 & 0.013 & 0.445 & 1.000 & 0.000 \\
\hline LP4 & 6.279 & 2.796 & 914 & 0.366 & 0.163 & 0.445 & 1.000 & 0.000 \\
\hline LP5 & 6.279 & 2.796 & 304 & 0.122 & 0.054 & 0.445 & 1.000 & 0.000 \\
\hline LP6 & 6.279 & 2.796 & 499 & 0.200 & 0.089 & 0.445 & 1.000 & 0.000 \\
\hline LP7 & 6.411 & 3.332 & 166 & 0.068 & 0.035 & 0.520 & 1.000 & 0.000 \\
\hline LP8 & 6.411 & 3.33 & 533 & 0.218 & 0.113 & 0.520 & 1.000 & 0.000 \\
\hline 99 & 6.411 & 3.33 & 530 & 217 & 0.113 & 0.520 & 1.000 & 0.000 \\
\hline LP10 & 6.411 & 3.332 & 209 & 0.086 & 0.044 & 0.520 & 1.000 & 0.000 \\
\hline 211 & 6.279 & 2.796 & 612 & 245 & 0.109 & 0.445 & 1.000 & 0.000 \\
\hline 12 & 6.931 & 9.115 & 465 & 0.206 & 0.271 & 1.315 & 0.999 & 0.001 \\
\hline LP1 & 6.931 & 9.11 & 146 & 0.065 & 0.085 & 1.3 & 0.999 & 0.001 \\
\hline & 6.931 & & 530 & & & & 0.999 & 0.001 \\
\hline & 7.042 & 9.483 & 465 & 0.209 & 0.282 & 1.347 & 0.999 & 0.001 \\
\hline & 7.177 & 9.923 & 103 & 0.047 & 0.065 & 1.383 & 0.999 & 0.001 \\
\hline & 7.177 & 9.923 & 43 & 0.020 & 0.027 & 1.383 & 0.999 & 0.001 \\
\hline & 7.182 & 9.973 & 65 & 0.030 & 0.041 & 1.389 & 0.999 & 0.001 \\
\hline 117 & 6.931 & 9.115 & $1 / 8$ & 0.079 & 0.104 & 1.315 & 0.999 & 0.001 \\
\hline
\end{tabular}

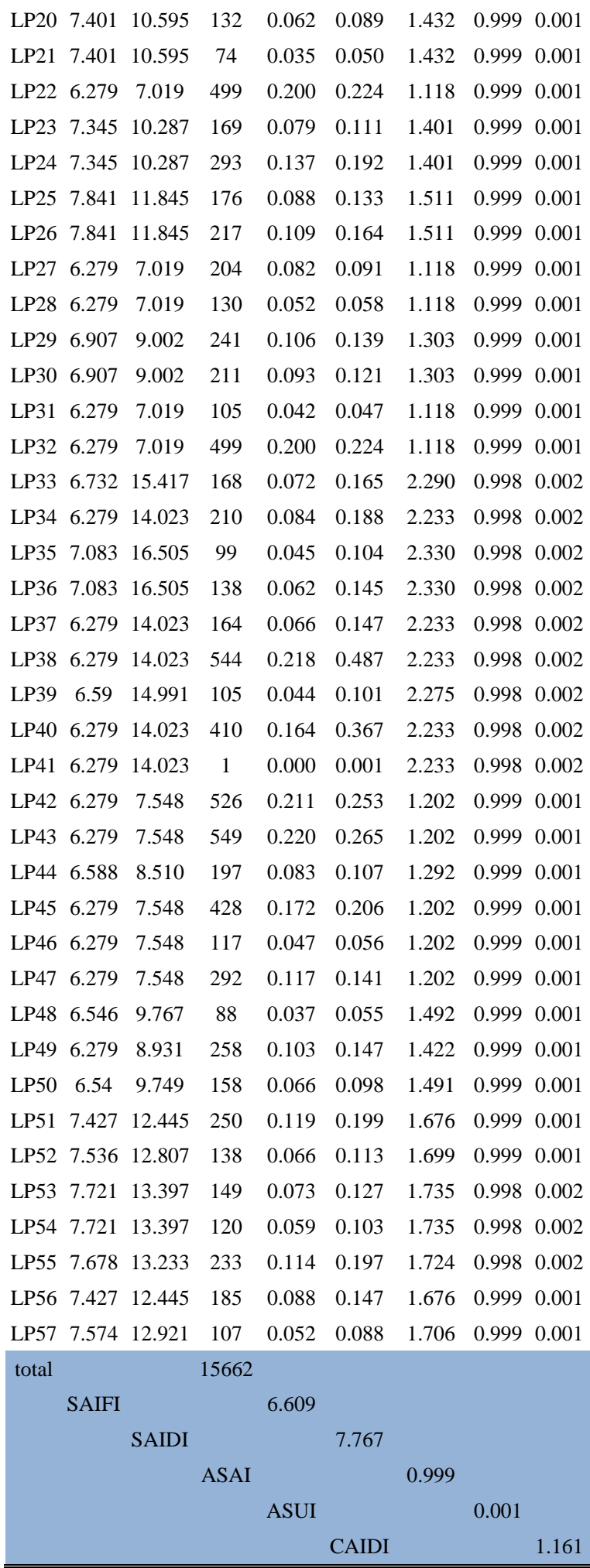

Dari hasil perhitungan FMEA dengan excel didapatkan bahwa Penyulang Sukodono mempunyai indeks SAIFI sebesar 6.609, SAIDI sebesar 7.767, dan CAIDI sebesar 1.161

D. Hasil Evaluasi Perhitungan Excel vs Simulasi Etap Berikut merupakan hasilnya:

TABEL 5. EXCEL VS ETAP P. SUKODONO

\begin{tabular}{ccc}
\hline \hline & EXCEL & ETAP \\
\hline SAIFI & 6.6088 & 6.5654 \\
SAIDI & 7.7674 & 7.5806 \\
CAIDI & 1.1611 & 1.1550 \\
ASAI & 0.99895 & 0.9991
\end{tabular}




\section{$\begin{array}{lll}\text { ASUI } \quad 0.00105 & 0.00087\end{array}$}

Dengan mengasumsikan bahwa simulasi Etap sebagai acuan maka dari tabel diatas menunjukkan bahwa adanya selisih indeks keandalan antara perhitungan menggunakan Software Etap dan manual Excel. Hal ini dikarenakan adanya perbedaan metode yang digunakan sehingga menimbulkan selisih namun tidak signifikan.

E. Hasil Evaluasi Perhitungan Excel semua Penyulang.

Berikut merupakan Hasil Excel FMEA :

TAbel 6. Hasil Perhitungan ExCEl Semua PenyUlang

\begin{tabular}{cccccc}
\hline \hline & Sukodono & Sudirman & Pronojiwo & Klakah & Keting \\
\hline SAIFI & 6.6088 & 2.64570 & 18.5027 & 19.0324 & 10.7917 \\
SAIDI & 7.7674 & 2.64915 & 21.1985 & 29.8218 & 8.6927 \\
CAIDI & 1.1611 & 1.00131 & 1.1457 & 1.5669 & 0.8055 \\
ASAI & 0.99895 & 0.99967 & 0.99743 & 0.99647 & 0.99888 \\
ASUI & 0.00105 & 0.00033 & 0.00257 & 0.00353 & 0.00112 \\
\hline \hline
\end{tabular}

Jika dilihat pada grafik maka:

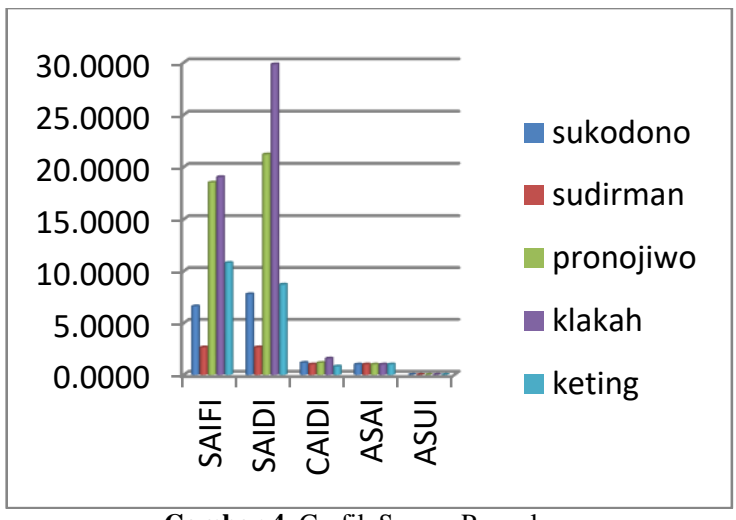

Gambar 4. Grafik Semua Penyulang

Dari Data Grafik Diatas disesuaikan dengan panjang masing-masing penyulang maka didapat semakin panjang saluran maka frekuensi kegagalan dari penyulang akan semakin tinggi, dibuktikan dengan nilai SAIFI yang tertinggi yaitu penyulang klakah, begitu juga dengan durasi akan semakin panjang diibuktikan dengan nilai SAIDI. Untuk Durasi juga melibatkan banyaknya sectionalizer, jika sectionalizer jumlahnya banyak dan penenpatannya optimal maka durasi akan bisa diredam.

\section{F. Upaya Perbaikan Keandalan Penyulang Sukodono}

Pada umumnya ada dua cara untuk memperbaiki keandalan suatu system tenaga listrik, cara pertama adalah mengurangi frekuensi terjadinya gangguan, dan kedua adalah mengurangi durasi gangguan. Berikut merupakan hasil upaya perbaikan keandalan penyulang sukodono :

TABel 7. PERbaikan KeANDAlan PENyUlang SuKodono

\begin{tabular}{cccc}
\hline \hline & Sebelum Perbaikan & Setelah Perbaikan & Turun \\
\hline SAIFI & 6.6088 & 5.4176 & $18.02 \%$ \\
SAIDI & 7.6737 & 6.4431 & $16.04 \%$ \\
CAIDI & 1.1610 & 1.1892 & $2.43 \%$ \\
ASAI & 0.99895 & 0.99912 & $0.02 \%$ \\
ASUI & 0.00104 & 0.00088 & $15.38 \%$ \\
\hline \hline
\end{tabular}

Jika dilihat pada grafik maka :

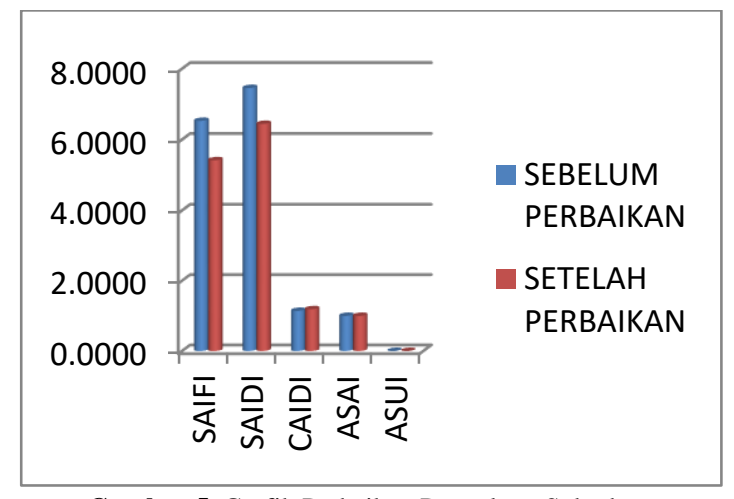

Gambar 5. Grafik Perbaikan Penyulang Sukodono

Dari upaya didapat hasil SAIFI yang awalnya bernilai 6.6088 turun menjadi bernilai 5.4176 hal ini dikarenakan oleh penambahan fuse yang secara langsung dapat mengurangi lamda per-Load Point, dan SAIDI yang awalnya bernilai 7.6737 turun menjadi bernilai 6.4431 hal ini dikarenakan penambahan sectionalizer sehingga mengurangi durasi akibat perubahan repair time menjadi waktu switching time pada Load Point yang terlokalisir

\section{KESIMPULAN}

Berdasarkan hasil yang didapatkan dari simulasi dan analisis pada tugas akhir ini, dapat diambil beberapa kesimpulan sebagai berikut:

1. Pada Hasil Evaluasi Keandalan sistem distribusi $20 \mathrm{kV}$ di Rayon Lumajang menggunakan FMEA maka didapat hasil :

- Penyulang sukodono

$$
\text { SAIFI }=6.6088 \quad \text { SAIDI }=7.7674
$$

- Penyulang klakah

$$
\text { SAIFI }=19.0324 \quad \text { SAIDI }=29.8218
$$

- Penyulang pronojiwo

$$
\text { SAIFI }=18.5027 \text { SAIDI }=21.1985
$$

- $\quad$ Penyulang keting

$$
\text { SAIFI }=10.7917 \quad \text { SAIDI }=8.6927
$$

- Penyulang sudirman

$$
\text { SAIFI }=2.64570 \text { SAIDI }=2.64915
$$

2. Pada Upaya perbaikan pada penyulang sukodono didapat hasil :

- Pada penyulang sukodono indeks keandalan SAIFI sebelum adanya upaya perbaikan adalah sebesar 6.6088 dan setelah adanya upaya perbaikan dengan adanya penambahan komponen fuse maka indeks keandalan SAIFI menjadi 5.4176

- Pada penyulang sukodono indeks keandalan SAIDI sebelum adanya upaya perbaikan adalah sebesar 7.6737 dan setelah adanya upaya perbaikan dengan adanya penambahan komponen sectionalizer maka indeks keandalan SAIDI menjadi 6.4431

3. Karena Frekuensi kegagalan pada Saluran yang sangat tinggi dibandingkan dengan komponen penyumbang kegagalan lain seperti trafo, switch dan CB, maka semakin panjang saluran mengakibatkan frekuensi kegagalan dalam system akan semakin tinggi dibuktikan dengan semakin besarnya nilai Indeks SAIFI, begitu pula dengan SAIDI yang ikut naik diakibatkan oleh durasi yang mengikuti besaran frekuensi kegagalan. Dan untuk mengkompensasi besarnya nilai SAIFI dan SAIDI yang mengartikan bahwa system tidak handal maka dibutuhkan komponen sectionalizer dan fuse yang cukup agar 


\section{system bekerja optimal}

\section{DAFTAR PUSTAKA}

[1] Roy Billinton and Ronald N allan.1996. Reliabillity evaluation of power systems. New York: Plenum Press

[2] Suhardi, Bambang. 2008. Teknik Distribusi Tenaga Listrik. Jakarta: Direktorat Pembinaan sekolah menengah kejuruan, Direktorat Jendral manajemen Pendidikan Dasar dan Menengah, Departemen Pendidikan Nasional.

[3] Engelberth, tigor. 2012. Analisis keandalan system distribusi 20KV di PT.PLN (Persero) area jaringan bali selatan dengan menggunakan metode FMEA. Surabaya: ITS
[4] Nugroho, andhito sukmoyo.2012. Studi keandalan sistem distribusi $20 \mathrm{kV}$ di Bengkulu dengan metode FMEA. Surabaya: ITS

[5] Liliana. 2012. Analisa rpn terhadap keandalan peralatan pengaman jaringan distribusi dengan metode fmea pln cabang pekanbaru rayon panam.riau: UIN suskam riau

[6] Tim PLN. 1985. Keandalan pada Sistem Distribusi $20 \mathrm{kV}$ dan 6 $k V$. Jakarta: Departemen Pertambangan dan Energi

[7] Tim PLN. 1985. Petunjuk Pemilihan dan Penggunaan Pelebur pada Sistem Distribusi Tegangan Menengah. Jakarta: Departemen Pertambangan dan Energi 